\title{
Migração Negra: Um Estado da arte sobre a presença da população negra na Amazônia $^{1}$
}

Black Migration: A state of art on the presence of black population in Amazon

\author{
Ketno Lucas Santiago ${ }^{1}$ \\ Francisco Pereira Smith Júnior ${ }^{*}$
}

\section{Resumo}

Esta pesquisa é fruto da realização de um Estado da Arte sobre a categoria migração negra. O objetivo principal é identificar estudos acadêmicos, principalmente teses, dissertações, que tratam sobre a temática. Apresentar um panorama a respeito do conceito de migração negra, sua frequência e aplicabilidade teórica. Articular os conceitos migratórios identificados com os estudos de autores que trabalham a temática, bem como apontar indicativos para uma melhor conceituação da categoria. Metodologicamente, o caminho percorrido é de cunho historiográfico, por meio de um levantamento bibliográfico, identificando teorias que contribuem para o estabelecimento de um diálogo entre os conceitos sugeridos. Resultados preliminares indicam que a chegada do povo africano no Brasil e na Região Amazônica se deu por meio de um processo migratório. No estudo, recorre-se ao aos autores Sayad (1998), Klein (2000) e Ianni (2004), que abordam a temática em questão. Estabelece-se um diálogo com os autores, abordando uma variação do conceito de migração, de forma a contribuir com elementos que justifiquem a afirmação de que a migração negra possui diferenças e similaridade com outros processos migratórios vivenciados por outras populações pelo mundo, porém são as similaridades que a define enquanto migração negra.

Palavras-chave: Povos africanos. migração negra. Amazônia.

\begin{abstract}
This research is the result of the realization of a State of Art on the black migration category. The main objective is to identify academic studies, mainly theses, dissertations, which deal with the theme. To present an overview about the concept of black migration, its frequency and theoretical applicability. To articulate the migratory concepts identified with the studies of authors who work on the theme, as well as to indicate indicatives for a better conceptualization of the category. Methodologically the path taken is historiographic, through a bibliographic survey, identifying theories that contribute to the establishment of a dialogue between the suggested concepts. Preliminary results indicate that the arrival of the African people in Brazil and in the Amazon Region was through a migratory process. The authors, Sayad (1998), Klein (2000) and Ianni (2004), who address the theme were identified. In this sense, it was possible to establish a dialogue with the authors, addressing a variation of the concept of

\footnotetext{
${ }^{1}$ Acadêmico do Mestrado do Programa de Pós-Graduação em Linguagens e Saberes da Amazônia PPLSA/Campus Bragança (UFPA). Bolsista CAPES. Especialista na Docência do Ensino Superior, Historiador. Membro do GELCONPE. E-mail: ketnolucas@gmail.com

2 Professor Doutor Adjunto IV (UFPA). Vice-coordenador do Programa de Pós-graduação em Letras, Linguagens e Saberes na Amazônia (PPLSA). Coordenador do Grupo de Estudos de Literatura Comparada do Nordeste Paraense - GELCONPE. E-mail: fsmith@ufpa.br
} 
migration, contributing elements that justify the statement that black migration, has differences and similarity with other migratory processes, experienced by other populations around the world, but It is the similarities that define them as black migration.

Keywords: African peoples. black migration. Amazon.

\section{Introdução}

A migração negra ${ }^{3}$ é um fenômeno constituído ao longo da história da humanidade, um processo de deslocamento do povo negro de sua terra natal para outro território ${ }^{3}$ de modo forçado, diferenciando-se do conceito de migração adotado por Sayad (1998) que, segundo ele, é realizado de forma espontânea, por motivações variadas. Esse povo foi forçado a sair de seu país de origem, levado a se estabelecer em outras localidades do mundo, sobretudo na Europa, América do Norte e, principalmente, na América do Sul, como foi o caso da presença da população negra na região Amazônica e no Brasil escravista. Um exemplo desse movimento migratório foi à saga (retratada na tela abaixo), em que milhares de negros se deslocaram no período de 1890 até o período da $2^{\mathrm{a}}$ grande guerra mundial, migrando do sul para as grandes cidades industriais do norte dos Estados Unidos, dentre elas, as cidades de Chicago, Detroit e Nova York. ${ }^{4}$

Figura 01 - The Migration Serie, Jacob Lawrence

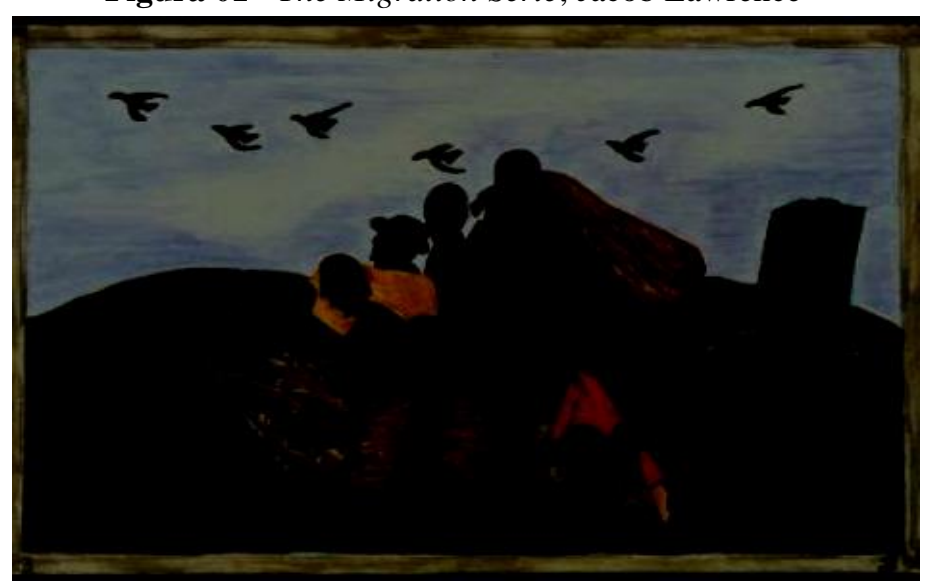

Fonte: www.vermelho.org.br/noticia/271320-1

\footnotetext{
3 A migração negra consiste em um movimento populacional compulsório e forçado com marcas significativas em sua identidade. Marcado por um processo de deslocamento de sua terra de origem para outros territórios no mundo.

3 Território. 1. Extensão considerável da Terra; área de um país, província, cidade, etc.; 2. Unidade político-administrativa subordinada à União. Oliveira, Cêurio de Dicionário cartográfico I Cêurio de Oliveira • 4. ed. - Rio de Janeiro: IBGE, 1993. 646p.: il.

4 Muitos desses negros fugiam da pobreza, da exploração nas fazendas de algodão e do racismo (segregacionismo).
} 
Na tela de Jacob Lawrence é retratado o cotidiano de muitos negros e a sua própria história, visto que o pintor foi um imigrante refugiado na cidade de Nova York. Portanto, o tema da migração negra ultrapassa o universo das discussões ao ponto de ser retrato da vida na arte.

O Continente Africano, antes e durante o período de comercialização da população negra, foi marcado pelo tráfego de pessoas escravizadas, sendo afetado por várias migrações forçadas. "Desde tempos imemoriais, muitos africanos foram vitimados por fluxos migratórios compulsórios que conectaram a África com diversas partes do mundo" (FERREIRA, 2018, p. 51), porém esses processos migratórios não tinham custado tanto a vida do povo africano como custou nesse tempo histórico de tráfico para as Américas.

Deslocados para várias partes do mundo, principalmente para as Américas e para o Brasil, através do tráfico negreiro, mercadores comercializavam a população negra em condição de escravidão com os grandes proprietários de terra, fazendeiros, mineradores e comerciantes brasileiros que tinham o interesse de ampliar a mão de obra escrava em suas propriedades de terra (COSTA, 2007). Prática garantida e oficializada pelo Estado durante o Brasil Colônia e Império até o ano de 1888, com a publicação da Lei Áurea ${ }^{5}$ (BRASIL, 2012, p. 514).

No Brasil, após a abolição da escravidão, ocorreu outro deslocamento, desta vez de forma interna, em que a população negra, motivada pela busca de melhores condições de vida (aqui identificada enquanto um processo integrante do fluxo migratório da população negra), se deslocou internamente entre estados e províncias, do interior para capital, da capital para o interior, identificadas na conceituação de Costa (2007).

Esse processo migratório da população recém liberta da escravidão desenvolveu uma migração interna em busca de trabalho e moradia, afinal os escravizados, "marcados pelo legado da escravidão, não conseguiram, salvo raras exceções, competir com o estrangeiro no mercado de trabalho" (COSTA, 2007, p. 341). A população negra foi historicamente forçada a deixar o seu local de origem e se deslocar para outras localidades, com o objetivo de garantir a sua subsistência.

A chegada dos primeiros cativos africanos introduzidos na região Amazônica é datada do início do século XVII, pelos ingleses (SALLES, 2005), que tinham o objetivo

\footnotetext{
5 “Lei n 3.353, de 13 de Maio de 1888”, declara extinta a escravidão no Brasil.
} 
de realizar um grande empreendimento agrário na região, como o plantio de cana e produção de açúcar. "Todavia, os ingleses e os demais conquistadores holandeses, franceses e irlandeses acabaram sendo expulsos da região amazônica pelo avanço luso a serviço da Coroa espanhola" (BEZERRA NETO, 2012, p. 25). Além da exploração das “drogas do sertão", também estavam preocupados com a colonização da região.

Considera-se, portanto, que a migração negra foi um fenômeno social em que arrancaram o povo negro da terra de origem por meio de uma migração forçada, submeteram essa população a um regime de escravidão, sendo uma média de 300 anos de trabalhos forçados e, após a abolição, sem direitos e jogados às margens da sociedade, essa população parte em uma migração interna em busca de melhores condições de vida; um tempo histórico de negação do homem pelo homem, de aviltação de vidas humanas. Por esse motivo, se faz necessária uma maior e melhor definição do conceito migração negra, por meio de um Estado da Arte, sendo realizado um levantamento bibliográfico sobre o conceito, com objetivo de identificar trabalhos acadêmicos (Teses e Dissertações) que tratam da temática. Além de verificar o volume de pesquisas voltadas para o assunto, confirmando ou não a aplicabilidade do conceito ao processo migratório.

O Estado da Arte também contribui para estabelecer uma diferenciação entre o conceito de migração negra e diáspora, entendendo que a aplicabilidade do conceito de migração negra nesta produção textual é meramente uma opção política, sem a intenção de rivalizar com o conceito de diáspora, muito utilizado na academia. Pois no dizer do pesquisador Stuart Hall (2003) sobre o processo migratório, "a pobreza, o subdesenvolvimento, a falta de oportunidades - os legados do Império em toda parte podem forçar as pessoas a migrar - o que causa o espalhamento - a dispersão" (HALL, 2003, p. 28). Na fala do autor, é possível perceber a relação entre diáspora e migração, suas proximidades e distâncias.

As semelhanças e diferenças entre os dois conceitos contribui para a possibilidade de um diálogo entre essas categorias e as teorias desenvolvidas a partir desses conceitos, conforme afirma Melo (2011, p. 12) ao falar sobre a importância de se fazer referência ao conceito de diáspora, porque trata sobre o espalhamento da população negra africana pelo mundo enquanto um movimento diaspórico.

A autora em sua pesquisa optou em trabalhar o conceito migração negra relacionando-o ao deslocamento da população negra. Por outro lado, ela também apresenta sua leitura sobre diáspora ao afirmar que "o conceito fechado de diáspora se 
apoia sobre uma concepção binária de diferença. Está fundado sobre a construção de uma fronteira de exclusão e depende de um "outro" de uma posição rígida entre o dentro e o fora ${ }^{6 "}$ (MELO, 2011, p. 18).

Com essa diferenciação estabelecida, partimos para o Estado da Arte que terá como foco mapear as produções acadêmicas sobre o conceito de migração negra, enquanto um conceito geral no Brasil e, principalmente, na Região Amazônica. Para isso, foram priorizados três sites de periódicos renomados e de reconhecida relevância acadêmica, o site do Sistema de Bibliotecas da Universidade de Campinas ${ }^{7}$ UNICAMP; o site da Coordenação de Aperfeiçoamento Pessoal, órgão do Ministério da Educação e Cultura $^{8}$ - CAPES e o site da Biblioteca Central da Universidade Federal do Pará $^{9}$ - UFPA, para o levantamento de dissertações e teses.

O método para localizar o conceito pesquisado leva em consideração o "momento em que se obtém as informações necessárias e que serão alvo de análise" (MOROZ, 2006, p. 83), realizando-se, em seguida, o tratamento dos dados coletados. Assim, as informações foram tabuladas e organizadas em quadros. Para apresentar os dados conforme um raciocínio demonstrativo, consideramos que a "construção lógica ou síntese é a coordenação inteligente das ideias conforme as exigências racionais da sistematização própria do trabalho" (SEVERINO, 2007, p. 148).

A escolha pela realização do levantamento bibliográfico por meio do Estado da Arte, em site acadêmicos, foi primada pela quantidade dos trabalhos, pelo foco na temática proposta, pela capacidade em armazenamento dos dados, pela atualização das pesquisas acadêmicas. E, ainda, a opção pelo site da Biblioteca da UFPA se dá pela adição do fator regional ao verificar produções acadêmicas desenvolvidas no âmbito da região amazônica.

Nesse sentido, foram localizados dados do Estado da Arte, considerando o descritor proposto, bem como o período temporal sugerido, entre a década de 80 ao ano de 2018, onde o conceito é apresentado nos títulos das pesquisas. Em seguida, deu-se a seleção dos textos (resumo e texto na íntegra) e das palavras-chave, em pesquisas que abordam a temática com maior relevância, para em outro momento estabelecer um

\footnotetext{
6 A autora faz referência à pesquisa desenvolvida em HALL, Stuart. Da diáspora: Identidade e mediações culturais. Belo Horizonte: Editora UFMG, 2003.

7 Pesquisa desenvolvida no site do Sistema de Bibliotecas da UNICAMP. https://goo.gl/XPg2dt. Acessado dia 13/08/2018

8 Pesquisa desenvolvida no site dos Periódicos da CAPES. https://goo.gl/4ZoV75. Acessado dia 13/08/2018.

${ }_{9}^{9}$ Pesquisa desenvolvida no site da Biblioteca da UFPA. http://bc.ufpa.br/. Acessado dia 13/08/2018.
} 
diálogo com autores sobre as temáticas correlatas e, por último, foi exibido um amálgama das ideias apresentadas.

O Estado da Arte apresenta os dados coletados sobre o conceito de migração negra enquanto um processo de deslocamento dessa população do Continente Africano para o Brasil e para a região Amazônica. Esse levantamento possibilitou estabelecer diálogo com os autores em estudo.

\section{Migração Negra: a construção de um conceito por meio do estado da arte}

A presente seção retrata a busca pelo conceito de migração negra a partir dessa categoria analisada. Para isso, fez-se necessário mapear a produção acadêmica em periódicos, a fim de verificar teoricamente como tem sido tratada por pesquisadores a discussão sobre o processo de migração dos negros para o Brasil e para a Amazônia Paraense ${ }^{10}$.

A opção por pesquisar a região Amazônica é por entender a importância e o significado da região para o país e para o mundo, entendendo a Amazônia enquanto um território amplo, constituindo um objeto de análise sob a ótica de vários campos do conhecimento, com intuito de compreender os novos processos sociopolíticos regionais. "Em meio a esses processos, ações públicas locais, em especial aquelas envolvendo a criação e gestão de Unidades de Conservação, projetos de assentamento, territórios quilombolas e indígenas" (TEISSERENC; SANT'ANA JÚNIOR; ESTERCI, 2016, p. 05), áreas protegidas de modo geral, vem-se buscando compreender as dinâmicas sociais apresentadas.

Para alcançar o objetivo proposto nesta pesquisa, o referencial teóricometodológico tem como base autores do campo das Ciências Humanas, delimitando um tempo histórico correspondente aos anos de 1980 a 2018 de publicações de teses e dissertações. O período definido teve o objetivo de analisar as produções, que iniciaram no tempo histórico da revisão da historiografia, período "onde os cientistas brasileiros estão procurando rever (ou reabilitar?) o modo de produção escravista no Brasil" (MOURA, 1994, p. 19). Esse processo se inicia por volta da década de 80.

É significativo ressaltar a importante contribuição do trabalho realizado nos anos 90 pelo Centro Nacional de Referência Historiográfica - CNRH - sob a direção e a

\footnotetext{
${ }^{10}$ Entendendo a Amazônia enquanto um espaço amplo e plural, com grande extensão territorial que se estende por 9 países, 9 estados brasileiros, 7 estados na região norte do país. Apresentando características diferenciadas. (ARAGÓN, 2013).
} 
autoria dos pesquisadores Carlos Fico e Ronald Polito, os quais produziram uma avaliação sistemática e catalográfica da produção historiográfica no Brasil dos anos 80 . Essa pesquisa apresenta um panorama das diversas temáticas e tendências da época e a divisão por períodos históricos no nível de uma abordagem conceitual.

A pesquisa desenvolvida pelo CNRH faz um levantamento das produções bibliográficas desenvolvidas, principalmente, das teses e das dissertações no Brasil. Faz referência às fragilidades dos trabalhos acadêmicos da década de 70 e à ocorrência de uma mudança significativa nos anos 80 ao apresentar melhor procedimento acadêmico, "com uma diminuição dos casos realmente fracos e uma sensível ampliação dos trabalhos de maior qualidade, principalmente, entre as teses de doutorado" (FICO; POLITO, 1994 p. 153). Nesse sentido, essa pesquisa contribui para justificar o marco temporal aplicado no Estado da Arte, garantindo assim uma maior incursão teórica.

\section{Migração Negra: a construção de um conceito}

Ao pesquisar a categoria migração negra no Sistema de Bibliotecas da UNICAMP e no Repositório da Produção Científica e Intelectual da Unicamp, identificou-se pesquisas que tratam da temática. Foram 114 artigos, 25 dissertações e teses, 7 livros e 4 recursos textuais. Dentre as dissertações e teses acadêmicas, é possível destacar algumas pesquisas que dialogam com o objeto deste artigo.

Foi possível identificar uma pesquisa que trata, entre outros assuntos, sobre o fato histórico conhecido como The Great Migration ${ }^{11}$, no qual milhões de negros saíram do Sul e foram para o Norte dos EUA em busca de melhores condições de vida. Para ilustrar o assunto, a autora cita notícias da imprensa negra veiculadas na cidade de Nova York que relatam os números de migrantes na cidade. Intitulada "Migração dos Negros", a matéria publicada no The Crisis, em junho de 1917, "preconiza [...] um deslocamento de 250.000 "trabalhadores de cor" no primeiro semestre daquele ano" 12 (XAVIER, 2012, p.25).

Em outro trabalho acadêmico encontrado, é possível perceber o processo migratório da população negra, que sai da região de São Paulo e migra para outras regiões do país, no período do pós-abolição. Para ilustrar, a autora cita um noticiário do

\footnotetext{
${ }^{11}$ A autora aborda sobre o fato histórico ocorrido no EUA, conhecido como a Grande Migração Negra, que ocorreu no período do final do Século XIX e início do Século XX.

${ }^{12}$ A notícia trazia informações dos êxodos nos seguintes estados: Alabama: 60.000; Tennessee: 22.000; Flórida: 12.000; Geórgia: 10.000; Virgínia: 3.000; Carolina do Norte: 2.000; Kentucky: 3.000; Carolina do Sul: 2.000; Arkansas: 2.000; Mississipi: 2.000. The Horizon, "Industry", The Crisis, v.13, n. 3, janeiro de 1917, p. 143. (XAVIER, 2012, p. 25).
} 
jornal com o título "Os pretos desaparecem de São Paulo"13, dizendo que depois da publicação da Lei Áurea, de 13 de maio de 1888, "tem-se notado que a raça preta vai se desaparecendo aos poucos d'este Estado" (SILVA, 2001, p. 11). A autora justifica esse fato dizendo que esse processo migratório se deu por causa dos maus tratos, que quase obrigaram os libertos a buscar outros espaços para morar, com intuito de garantir melhor condição de sobrevivência.

Destaque também para a pesquisa que trata da grande "Migração Negra Americana" que ocorreu em meados do século XX, entre 1930 e 1960, considerado pela autora como a maior movimentação humana interna ocorrida nos Estados Unidos nesse período. Segundo a autora, em relação à migração negra, "os afro-americanos têm sido moldados por diferentes migrações talvez mais do que qualquer outra etnia das Américas" (COSTA, BRANCA, 2007, p. 07).

Ao pesquisar no site da Biblioteca Central da UFPA não foram identificadas pesquisas na categoria migração negra. Mostrando que a temática e o debate possui grande relevância acadêmica e social, pois demostra ineditismo na pesquisa sobre migrações voltadas para a população negra.

Ao pesquisar o site dos Periódicos da CAPES, em seu catálogo de teses e dissertações, foi possível identificar 106 artigos, 149 teses e dissertações e 38 livros. Ao focalizar teses e dissertações, foram identificadas 31 teses, 99 dissertações de mestrado e 19 dissertações de mestrado profissional. Entre as pesquisas destaca-se a dissertação que trata da presença dos imigrantes senegaleses na cidade de São Paulo, trabalhando a questão dos direitos humanos, discriminação racial e a legislação migratória vigente, indicando ainda que o processo migratório da população de Senegal é diferenciado, "tendo em vista que é uma migração negra e procedente do continente africano" (SANTOS NETO, 2017, p. 17), contribuindo assim para conceituar a categoria pesquisada.

Foi possível identificar também a pesquisa de doutoramento que trata sobre o trabalho voltado para desvendar o movimento de deslocamento das famílias rurais negras em Mimoso do Sul/ES e como se constituíram e fixaram na região. Nesse sentido, foi realizado um levantamento histórico para detectar como foi o processo de colonização e a presença escrava na região, remontando o período do século XIX. "Nesse período e nesse mesmo lugar, ainda que os esforços abolicionistas tentassem

${ }^{13}$ Notícia publicada no dia 27 de junho de 1897, no jornal “A Redenção” conforme afirma Silva (2001, p.11). 
manter escondido o trânsito de escravos, também movimentado por fugas e formação de quilombos, era ali identificado"14 (ALMEIDA, 2014, p. 29), assim, o autor constitui uma visão a respeito da migração negra.

Ao reconhecer a tese de Oliveira (2015), foi possível perceber que o autor, em sua pesquisa, aborda os conceitos de cultura, identidade, quilombo e de massa. O catolicismo e a religião de matriz africana formam uma cultura nova, mostrando como a cultura da população negra africana sofreu um processo diaspórico de migração. Além disso, ele questiona "como esta celebração evoca a emergência identitária, como o quilombo é reconfigurado e ressemantizado" (OLIVEIRA, 2015, p. 19), fortalecendo a ideia de que o conceito de migração negra está associado ao debate cultural e indenitário.

Quadro I: Síntese do Estado da Arte com descritor "migração negra"

\begin{tabular}{|c|c|c|c|}
\hline \multicolumn{4}{|c|}{ SISTEMA DE BIBLIOTECAS DA UNICAMP - SBU } \\
\hline $\mathbf{N}^{\mathbf{0}}$ & Recurso & Agente/Ano & Resumo \\
\hline 1 & Tese & Xavier (2012) & $\begin{array}{l}\text { "A tese investiga as representações femininas } \\
\text { presentes em propagandas de produtos de } \\
\text { clareamento de pele da indústria cosmética, entre os } \\
\text { anos } 1890 \text { e 1930, conhecida como a Grande } \\
\text { Migração Negra". }\end{array}$ \\
\hline 2 & Tese & Silva (2001) & $\begin{array}{l}\text { "Examina a migração de ex-escravos e afro- } \\
\text { descendentes do estado de São Paulo rumo à cidade } \\
\text { do Rio de Janeiro, pós-abolição da escravidão (1888- } \\
\text { 1926)". }\end{array}$ \\
\hline 3 & $\begin{array}{l}\text { Dissertação } \\
\text { de Mestrado }\end{array}$ & $\begin{array}{l}\text { Costa, Branca } \\
(2007)\end{array}$ & $\begin{array}{l}\text { "A Grande Migração Negra Americana do século } \\
\text { XX foi a maior movimentação humana interna } \\
\text { ocorrida nos Estados Unidos". }\end{array}$ \\
\hline 4 & $\begin{array}{l}\text { Dissertação } \\
\text { de Mestrado }\end{array}$ & Aguilar (2012) & $\begin{array}{l}\text { "A pesquisa analisa o período de itinerância de um } \\
\text { grupo familiar residente no quilombo Rincão dos } \\
\text { Caixões, no município de Jacuízinho, no Planalto } \\
\text { Médio do Rio Grande do Sul." }\end{array}$ \\
\hline 5 & $\begin{array}{l}\text { Dissertação } \\
\text { de Mestrado }\end{array}$ & Panta (2013) & $\begin{array}{l}\text { "A partir dos conceitos de migração e exílio, } \\
\text { desenvolve-se uma análise sobre o processo } \\
\text { migratório/exílio de Sigmund Freud." }\end{array}$ \\
\hline \multicolumn{4}{|c|}{ BIBLIOTECA CENTRAL DA UFPA } \\
\hline \multirow{2}{*}{\multicolumn{4}{|c|}{$\begin{array}{l}\text { *Não foram encontradas referências ao descritor "Migração Negra". } \\
\text { PERIÓDICOS DA CAPES }\end{array}$}} \\
\hline & & & \\
\hline 1 & Dissertação & $\begin{array}{l}\text { Santos Neto } \\
(2017)\end{array}$ & $\begin{array}{l}\text { "Entrevistas com imigrantes senegaleses na cidade de } \\
\text { São Paulo, as quais subsidiaram a redação de quatro } \\
\text { capítulos deste trabalho". }\end{array}$ \\
\hline 2 & Tese & Almeida (2014) & $\begin{array}{l}\text { "Trata dos movimentos de famílias que desde } \\
\text { Mimoso do Sul/ES enfrentam compostos de } \\
\text { relacionamentos de forças". }\end{array}$ \\
\hline
\end{tabular}

${ }^{14} \mathrm{O}$ autor Almeida (2014) cita OLIVEIRA, João Pacheco de. Uma etnologia dos "índios misturados"? Situação colonial, territorialização e fluxos culturais. Mana. 1998, vol. 4, n. 1, p. 47-77. 


\begin{tabular}{|l|l|l|l|}
\hline 3 & Tese & Oliveira (2015) & $\begin{array}{l}\text { "A missa dos quilombos, na qual a metáfora } \\
\text { quilombo é acionada em celebração eucarística como } \\
\text { manifestação de fé religiosa". }\end{array}$ \\
\hline 4 & Tese & Junior (2015) & $\begin{array}{l}\text { "A tese propõe traduzir a pesquisa de doutorado } \\
\text { realizada no cotidiano de uma escola municipal } \\
\text { carioca de Ensino Fundamental entre os anos de } 2012 \\
\text { e 2013". }\end{array}$ \\
\hline 5 & Tese & Souza (2014) & $\begin{array}{l}\text { "A tese apresenta a proposta central de analisar as } \\
\text { modificações verificadas na vivência cotidiana de } \\
\text { mulheres nordestinas de migração permanente, que } \\
\text { se deslocaram durante a década de 1990 para os } \\
\text { municípios de Iturama". }\end{array}$ \\
\hline
\end{tabular}

(Elaboração dos autores, 2018).

$\mathrm{Na}$ pesquisa descrita no Quadro I, produzida a partir do Estado da Arte, identificou-se que tais trabalhos abordam a temática em estudo e são voltados para o objetivo de categorizar pesquisas que apontam a migração negra. Assim, foi possível perceber que, de forma ampla, os autores discorrem sobre a temática migração negra com certa frequência, apresentando várias leituras em diversas áreas do conhecimento, com uma variedade de enfoques. Para dialogar com os autores e as pesquisas identificadas, apresentamos uma abordagem de pesquisadores que trabalham a temática, ajudando na construção de um conceito relativo à migração negra.

\section{Diálogo entre autores sobre o conceito de Migração Negra}

A migração acontece em um espaço físico e social, tem o sentido de ocupação do espaço territorial e de distribuição populacional, bem como está relacionada a questões sociais que envolvem um espaço qualificado em vários sentidos, "socialmente, economicamente, politicamente, culturalmente" (SAYAD, 1998, p. 15). É um deslocamento de pessoas em um determinado espaço, segundo Smith Júnior (2012, p. 19), a migração é um processo de migrar de um lugar para outro. Nesse sentido, entende-se o processo migratório enquanto um processo de deslocamento geográfico no tempo espaço.

A migração, portanto, de um espaço geográfico para outro acontece por uma tomada de decisão do migrante, representa uma ação originada por pessoas com diversas motivações, uma vez que carregam "sentimentos humanos, como o desejo em encontrar uma vida nova, alavancada pela esperança de vida próspera, de habitar em locais favoráveis à vida tranquila, por exemplo, distante principalmente de guerras e calamidades naturais" (SMITH JÚNIOR, 2012, p. 19). 
Migra-se pelas mais diversas motivações, em busca de lugares próximos, distantes e longínquos. "Sempre em busca de emprego, isto é, sempre empenhados em vender a sua força de trabalho, para comer, beber, vestir-se, abrigar-se, proteger a saúde, estudar, conquistar direitos políticos, civis e sociais" (IANNI, 2004, p. 94), entre outras motivações, buscando sempre garantir mais qualidade de vida e direitos individuais e coletivos para as suas famílias. Tal movimento é contrário à migração negra, pois o processo migratório da população negra não possui motivações, pelo contrário, se configura enquanto uma migração forçada.

A migração forçada é o "termo genérico usado para descrever um movimento de pessoas de forma forçosa, por meio de coerção, incluindo ameaça à vida e à sua subsistência, seja por causas naturais ou humanas"15 (OIM, 2006, p. 39). Como exemplo temos movimentos de refugiados e deslocados internos, bem como pessoas deslocadas por desastres naturais ou ambientais, desastres nucleares ou químicos, fome ou projetos de desenvolvimento. A migração negra forçada está relacionada à escravidão e ao tráfico de seres humanos, foi impulsionada por questões econômicas no avanço de fatores produtivos na Inglaterra e no mundo, pela Revolução Industrial ${ }^{16}$ e por traficantes de pessoas que fizeram o transporte de cativos africanos para o Brasil.

A migração do povo negro africano atravessou anos, um tempo de tráfico escravista, durante "séculos de migração forçada até a proibição do tráfico" (GLEDHIL, 2014, p. 24) de pessoas em condição de escravidão no atlântico, imposto pela GrãBretanha, no ano de 1808. Com o fim do tráfico no atlântico, os ingleses passaram a cobrar do Brasil medidas para acabar com a escravidão, o país pressionado iniciou um processo de flexibilização das leis escravistas, iniciado com a promulgação da Lei do Governo Feijó, de 07/11/1831 ${ }^{17}$, declarando livres todos as pessoas em condição de escravidão vindas de fora do império e impondo penalidades aos importadores de pessoas cativas. Mas essa lei não significou o fim do tráfico negreiro, pelo contrário, ela findou oficialmente apenas em 1850, com a publicação da Lei n ${ }^{\circ} 581$ (Lei Eusébio de Queiroz) - de 04/09/1850 ${ }^{18}$ (BRASIL, 2012).

A proibição da importação de africanos em condição de escravidão não acabou

\footnotetext{
15 Traduzido do Espanhol.

$16 \mathrm{O}$ conceito de Revolução Industrial designa um fenômeno histórico acontecido em tempo e lugar determinados: intensas transformações nas técnicas produtivas, realizadas na Inglaterra e parte da Escócia no século XVIII (SILVA, 2009, p. 370).

${ }^{17}$ Lei do Governo Feijó. Declara livres todos os escravos vindos de fora do Império, e impõe penas aos importadores dos mesmos escravos (BRASIL, 2012, p. 69).

${ }^{18}$ Lei Eusébio de Queiroz. Estabelece medidas para a repressão do tráfico de africanos neste Império. (BRASIL, 2012, p. 159).
} 
com o sistema escravista no Brasil, pois somente foi abolido com a publicação da Lei Áurea $\mathrm{N}^{\mathrm{o}} 3.353$ de $1888^{19}$, marcando um tempo histórico de mudanças na forma de trabalho pelo contexto de "urbanização e industrialização", em que mudanças estruturais estiveram presentes no cenário brasileiro (COSTA, 2007, p. 253).

A liberdade da população negra no período do Brasil Império não ocorreu de forma estrutural, devido à ausência do Estado, que deveria apresentar políticas sociais para incluir o negro na sociedade brasileira, pois haviam sido submetidos a um longo período de trabalhos forçados, sem garantia de direitos (moradia, profissão e salário), sendo agora obrigados a buscar outro modo de vida para a sua própria subsistência. Por essa razão, muitos realizaram um processo de migração interna no país.

O processo de urbanização e distribuição espacial da sociedade brasileira foi marcado por grandes fluxos migratórios, contribuindo significativamente para a urbanização, processo esse que se iniciou no final do século XIX e se estendendo até meados do século XX. O conceito de migração interna no Brasil consiste em um "fenômeno da dinâmica demográfica que contribuiu para profundar as transformações estruturais na sociedade brasileira, destacando sua importante contribuição na passagem para uma sociedade urbana-industrial"20 (BAENINGER, 1999, p. 13). Esse processo de urbanização e ocupação territorial incluiu o território Amazônico.

O processo migratório na região amazônica ocorre ao longo da história. A ocupação da Amazônia brasileira ocorreu de forma lenta, a presença do homem parece não fazer parte da realidade da floresta, assim como são narradas as histórias dos "viajantes que enlouqueciam ou que desapareciam ao tentar adentrar a lendária e gigantesca floresta tropical” (SOUZA, 2013, p. 34) ${ }^{21}$, ao relatar como as fronteiras amazônicas parecem ser intransponíveis, se comparadas a uma cidadela cercada por muros e sentinelas. Assim é a conquista da Amazônia para os migrantes vindo de outras regiões.

A migração interna causou um processo de concentração populacional que persiste até os dias atuais. "Sempre em busca de novas oportunidades de trabalho, contingentes populacionais deslocaram-se paulatinamente para as regiões cujas economias se desenvolviam mais rapidamente" (TAVARES, 2001, p. 02), contribuindo

${ }^{19}$ Lei Áurea. Lei Imperial n. ${ }^{\circ} 3.353$, sancionada em 13 de maio de 1888 , foi o diploma legal que extinguiu a escravidão no Brasil (BRASIL, 2012, p. 236).

${ }^{20}$ O autor cita Singer (1973), Lopes (1973), Lopes e Patarra (1975), Cano (1977), Graham e Holanda (1980), Faria (1991), dentre outros.

${ }^{21}$ O autor Souza (2013) relata a visão de Euclides da Cunha (2006, p. 17) no primeiro capítulo de $\grave{A}$ margem da História de 1909, com o emblemático título "Terra sem História (Amazônia)". 
de forma significativa para o processo de urbanização das cidades. A busca por melhores condições de vida foram foi o fator que contribuiu para a colonização na região amazônica, tanto que na década de 70 , motivados pela construção da Transamazônica, vários "migrantes da colonização dirigida" (SOUZA, 2013, p. 35) se deslocaram para a região, estimulados pelo Estado.

\section{A presença da população negra na Amazônia}

No início do século XVII, a Região Amazônica era compreendida entre os “Estados do Pará e Maranhão e abrangia o Ceará, o Piauí, Maranhão, indo até os Estados do Amazonas e Acre e ainda passando por áreas de fronteira como Roraima, Rondônia e Amapá” (GOMES; SCHWARCS, 2018, p. 107). Segundo Salles (2005), a introdução definitiva da população negra na Amazônia Paraense, em seu espaço geográfico e no cotidiano português na América, acontece em 1616, com a fundação da cidade de Belém, a Capitania do Grão-Pará, conforme descreve a figura 02.

Figura 02: Capitania do Grão-Pará.

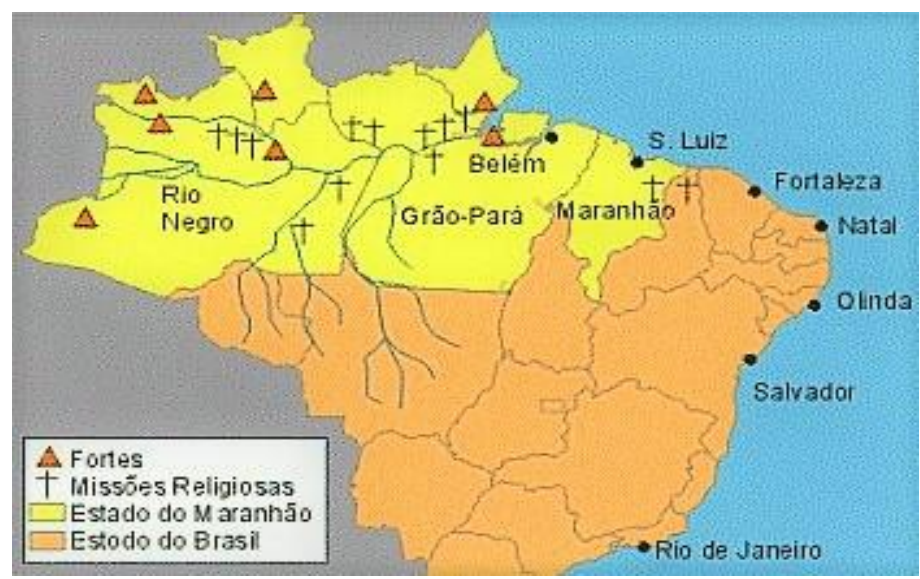

Fonte: http://twixar.me/Ds0K

O tráfico da população negra escravizada para as fazendas da região estava garantido pela Companhia de Comércio do Estado do Maranhão (1682), a Companhia do Comércio do Maranhão e Pará (1676-85) e a Companhia de Cacheu e Cabo Verde $(1690-1706)^{22}$. A Coroa Portuguesa utilizava as companhias para migrar forçosamente os cativos para a Região Amazônica. A historiografia remonta a existência de duas

\footnotetext{
${ }^{22}$ A fundação das companhias de comércio é citada no Dicionário da Escravidão e Liberdade. Textos de Flávio Gomes e Lilia Shwarcz (2018, p. 109).
} 
provisões régias, "que determinava a condução de negros da Costa de Guiné para o Maranhão e Pará por conta da fazenda real" (SALLES, 2005, p. 35), uma datada de 1662 e outra de 1680.

Além disso, documentos indicam a presença da população negra na capital da Província do Grão-Pará no século XVIII, nas áreas urbanas. “A população da freguesia urbana da Sé, a antiga e mais populosa cidade de Belém, mostra que entre os 5.276 habitantes, há 2.733 cativos, ou seja, mais de 50\% do contingente populacional”. (BEZERRA NETO, 2000, p. 17). Percebemos a expressiva presença da população cativa negra, uma vez que em Belém, capital da Província, viviam 8.573 habitantes, sendo 4.423 brancos (51,6\%); 3.051 cativos negros (35,6\%); e, 1.099 negros, índios e mestiços livres (12,8\%), segundo dados de Bezerra Neto (2000).

A forte presença de cativos na província de Belém também foi foco da pesquisa de Vicente Salles (2005), que apresentou vários números apontando a presença dos cativos na região durante as décadas do século XIX, mostrando que a população de cativos na Província do Grão-Pará estava diminuindo, ao dizer que no ano de 1872 possuía 23.090 cativos negros e, no ano de 1885, possuía 10.535, "de acordo com as informações das comarcas da Província do Grão-Pará, de Manoel Baena" (SALLES, 2005 p. 102). Na Comarca de Belém, capital da Província, havia 7.277 pessoas escravizadas.

A população negra escravizada na região da Amazônia Paraense tem destaque pela forte presença nos aspectos sociais, políticos, econômicos e culturais ao longo do século XIX. Na região do Nordeste Paraense, há significativa relevância, por ser uma região de fronteira com o Maranhão, rota de passagem dos negros cativos originados da África em trânsito seguindo para comarca de Belém. Na região, a força econômica vinha das propriedades de engenho, de lavouras, de minas de ouro e da criação de gado, conforme afirma Castro (2006, p. 11), motivando a fixação e a permanência dessa população de cativos que trafegava pela região.

O processo migratório de forma forçada se destacou na Amazônia Paraense por se tratar de uma rota comercial entre a Província do Maranhão e a Província do Pará. Após o fim da escravidão, a região recebeu uma parcela significativa de migrantes estrangeiros, incentivados pelo Estado para dar seguimento à produtividade. Entre esses migrantes que chegaram, "inclui-se uma parcela significativa de população negra" (SILVA, 2006, p. 53). Atraídos pela busca por trabalho e por fixação no solo, esse processo migratório se diferencia do anterior, confirmando que não existe um formato 
único para o estabelecimento e a fixação da população afro-brasileira na região.

Esse processo migratório interno de afro-brasileiros ocorreu dentro de outro contexto temporal e social, pois esse deslocamento aconteceu no final do século XIX e início do século XX. A incorporação dessa população, que estava chegando de outras regiões, acabou provocando uma nova organização do espaço urbano das cidades. O fator que contribuiu para essa fixação da população afro-brasileira foi a aceleração da "economia extrativista" (CASTRO, 2006, p. 34), entre outros fatores socioeconômicos.

A presença da população negra na região da Amazônia Paraense contribuiu para a constituição de um novo espaço urbano nas cidades, colaborou também para

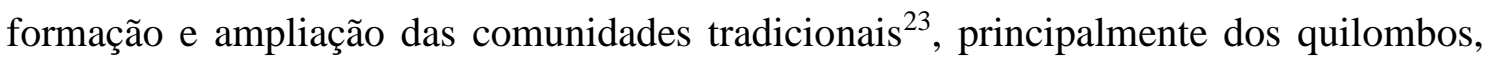
existentes até hoje e ressignificados com o tempo e com a legislação brasileira, a partir da Constituição de $1988^{24}$. A formação e a constituição dos quilombos na Amazônia Paraense integram um processo de construção identitária e cultural, que se relaciona com os movimentos migratórios e territoriais.

$\mathrm{Na}$ verdade, é possível dizer que as dinâmicas de conformação cultural diz respeito sobre "aspectos de nossas identidades que surgem de nosso "pertencimento" a culturas étnicas, raciais, linguísticas, religiosas e, acima de tudo, nacionais" (HALL, 2006, p. 08), desta forma, é possível dizer que a identidade da população negra, se constituiu por meio de seu pertencimento ao seu território. Portanto a sua adaptabilidade ao território nacional brasileiro, constituindo uma cultura afro-brasileira.

Nas comunidades tradicionais onde a população negra se faz presente, assim como em outras sociedades e comunidades, coexistem a cultura dominante em conflito com a cultura emergente. Na cultura dominante, parte se considera residual, porque algumas experiências, significados e valores não podem ser verificados, todavia são vividos e praticados enquanto resíduos. "Há exemplos reais disso em determinados valores religiosos, em contraste com a incorporação bastante evidente da maioria desses significados e valores dominantes" (WILLIANS, 2011, p. 56). A identidade cultural da população negra é emergente, é o novo querendo surgir, novas práticas, novos sentidos

\footnotetext{
${ }^{23}$ BRASIL. Decreto 6.040 de 07 de fevereiro de 2007. Art. $3^{\circ}$ inciso I - "Grupos culturalmente diferenciados e que se reconhecem como tais, que possuem formas próprias de organização social, que ocupam e usam territórios e recursos naturais como condição para sua reprodução cultural, social, religiosa, ancestral e econômica, utilizando conhecimentos, inovações e práticas gerados e transmitidos pela tradição". Disponível em: http://twixar.me/3Kzn. Acesso em: 21/03/2019.

24 _. Constituição Federal da República Federativa do Brasil de 1988. Disponível em: https://bit.ly/1dFiRrW. Acesso em17/05/2019. Os Artigos 215 e 216 tratam sobre o direito à preservação de sua própria cultura; o artigo 68 do ADCT, diz do direito à propriedade das terras de comunidades remanescentes de quilombos.
} 
e experiências.

Portanto, diante dos dados apresentados, é possível indicar os elementos propostos inicialmente na pesquisa, considerando que são dados iniciais de uma pesquisa em fase de construção, em que se apresentam indicativos, que contribuem para a construção conceitual da uma pesquisa mais ampla sobre a temática proposta.

\section{Considerações finais}

Conforme a realização do Estado da Arte, foi possível identificar estudos, teses e dissertações que tratam sobre o conceito de migração negra, indicando a variedade de possibilidades de aplicação teórica, perpassando a historiografia, a geografia, a sociologia, a antropologia, entre outras áreas do conhecimento. Os trabalhos apresentaram muitos pesquisadores que trabalham a categoria de análise, distribuídos em várias instituições de pesquisa do país. Somente no site da biblioteca da UFPA não foram encontrados trabalhos acadêmicos. Isso reforça a relevância da pesquisa ao apontar carência na abordagem do conceito migração negra, com recorte regional amazônico.

Nesse sentido, também foi possível estabelecer um diálogo com outros autores que, reconhecidamente, estudam essa temática e outros conceitos que se relacionam ao tema. Com esses elementos é possível dizer que o conceito de migração também se aplica ao deslocamento da população negra, com aspectos semelhantes e diferenciados da diáspora, pois são motivados por fatores diferenciados. Esse deslocamento é, predominantemente, atribuído ao fator econômico, movido pelo sistema que necessitava de maior mão de obra escrava, aliado a isso, há o deslocamento interno da população afro-brasileira no pós-abolição, que movimentou a população em busca de trabalho e melhores condições de vida.

Foi por meio da migração forçada e da migração interna que a população afrobrasileira se constituiu e se fixou na Amazônia Paraense, presentes nas cidades, mas principalmente contribuindo para a ampliação e formação de comunidades tradicionais na Amazônia. Destaque para a formação de quilombos, originados enquanto um processo de resistência ao escravismo brasileiro e mais tarde ressignificado pela legislação brasileira.

Portanto, podemos afirmar que a migração negra é um conceito histórico, amplo, plural, interdisciplinar, por envolver e dialogar com várias disciplinas, além de intercultural, por perpassar várias culturas. A migração negra está ligada ao conceito de 
migração, migração forçada, migração interna, territorialidade, povos tradicionais, quilombo, identidade, cultura, entre outros conceitos. Esses são alguns indicativos que apontam uma melhor aproximação da conceituação da temática.

\section{Referências}

AGUILAR, M. do Carmo Moreira. Famílias negras no planalto médio do Rio Grande do Sul (1940-1960): terra, migração e relações familiares. 2012. Dissertação (Mestrado) do Programa de Pós-Graduação em História do Instituto de Filosofia e Ciências Humanas- Universidade Federal do Rio Grande do Sul, Porto Alegre, 2012. Disponível em: https://encurtador.com.br/PZ468, Acessado dia 18/05/2019.

ALMEIDA, Marcos F. de. Desantropomorfização em Mimoso do Sul/ES: Outras Composições Através dos Relacionamentos de Forças. 2014. Tese (Doutorado em Antropologia Social) - Universidade Federal de Santa Catarina, Florianópolis, 2014.

ARAGÓN, Luis Eduardo. (org.). Migração Interna na Pan - Amazônia. Belém: NAEA, 2013. 253 p.: il.; $29 \mathrm{~cm}$.

BAENINGER, Rosana. Região, metrópole e interior: espaços ganhadores e espaços perdedores nas migrações recentes - Brasil 1980 - 1996. 1999. Tese (doutorado) Instituto de Filosofia e Ciências Humanas- Universidade Estadual de Campinas, Campinas - SP, 1999.

BRASIL. A Abolição no Parlamento: 65 anos de luta (1823-1888). 2 ed. Brasília: Senado Federal, Secretaria Especial de Editoração e Publicações, 2012, v. 1 e v. 2. Disponível em: https://goo.gl/TTf9PV. Acesso em: 18/05/2019.

BEZERRA NETO, José Maria. Escravidão negra no Pará: (Séculos XVII - XIX). 2 ed. Belém: Paka-Tatu, 2012.

Fugindo, sempre fugindo: escravidão, fugas escravas e fugitivos no Grão-Para (1840-1888). 2000. 373p. Dissertação (mestrado) - Universidade Estadual de Campinas, Instituto de Filosofia e Ciencias Humanas, Campinas, SP. Disponível em: http://www.repositorio.unicamp.br/handle/REPOSIP/279301. Acesso em: 26 jul. 2019.

CASTRO, Edna Maria Ramos de. (org.). Escravos e senhores de Bragança (Documentos históricos do século XIX, Região Bragantina, Pará). Belém: NAEA, 2006.

COSTA, Emília Viotti da. Da Monarquia à República - momentos decisivos. 8 ed. ver. e ampliada. São Paulo: Fundação Editora UNESP, 2007.

COSTA, Branca Maria Lopes de Albuquerque. Richard Wright e William 'Big Bill' Broonzy: diálogos narrativos da grande migração negra americana (1930-1960). 2007. Dissertação (Mestrado em Estudos Americanos) - Universidade Aberta - Porto, 2007, 185f. Disponível em: https://goo.gl/hmpfjj. Acesso em: 23 jul. 2018. 
FICO, Carlos; POLITO, Ronald. A historiografia brasileira nos últimos 20 anos: tentativa de avaliação crítica. VARIA HISTORIA, Belo Horizonte, n. 13, p. 147-163, jun. 1994. Disponível em: http://twixar.me/LhF1. Acesso em: 20 jul. 2019.

GLEDHILL, Helen Sabrina. Travessias racialistas no Atlântico Negro: reflexões sobre Booker T. Washington e Manuel R. Querino. (TESE) - Programa Multidisciplinar de Estudos Étnicos e Africanos da Faculdade de Filosofia e Ciências Humanas/Centro de Estudos Afro-Orientais - CEAO, da Universidade Federal da Bahia - Salvador - BA. 302 f. : il. 2014. Disponível em: https://encurtador.com.br/mAGTY. Acesso em $18 / 05 / 2019$.

GOMES, Flávio dos Santos; SCHWARCZ, Lilia Moritz. Dicionário da escravidão e liberdade: 50 textos críticos / Lilia Moritz Schwarcz e Flávio dos Santos Gomes (Orgs.). - 1aed. — São Paulo: Companhia das Letras, 2018.

HALL, Stuart. Da diáspora: Identidades e mediações culturais. Tradução Adelaine La Guardia Resende ... letall. - Belo Horizonte: Editora UFMG; Brasília: Representação da UNESCO no Brasil, 2003. 4M p. (Humanitas).

HALL, Stuart. A identidade cultural na pós-modernidade. Tradução Tomaz Tadeu da Silva e Guaracira Lopes Louro. 11. ed. Rio de Janeiro: DP\&A, 2006.

IANNI, Octavio. 1926 - Capitalismo, violência e terrorismo. Rio de Janeiro: Civilização Brasileira, 2004.

TEIXEIRA JUNIOR, Jose Carlos. Na narrativa dos MJs da Compositor: música, tecnologias e diáspora negra no cotidiano escolar. Tese (Doutorado em EDUCAÇÃO) Universidade do Estado do Rio de Janeiro, Rio de Janeiro/RJ, Biblioteca Depositária: REDE SIRIUS, 2015, $173 f$.

KLEIN, H. S. Migração Internacional na História da América. In: FAUSTO, Boris. (org.). Fazer a América. São Paulo: EDUSP, 2000. p. 13-31.

MELO, Ranyane. Diáspora e migração (um relato de pesquisa) eBook: Ranyane Melo, Lian Schneider (Orientadora da Presente Pesquisa do PIBIC) 1ªedição. 2011. E-book.

MOURA, Clovis. Dialética Radical do Brasil Negro. São Paulo: Editora Anita, 1994.

MOROZ, Melania; GIANFALDONI, Mônica Helena Tieppo Alves. O processo de pesquisa: iniciação. 2. ed. Brasília: Liber Livro Editora, 2006.

OIM. Glosario sobre Migración. Ginebra, Suiza, 2006. Disponível em: encurtador.com.br/qD045. Acesso em: 21 abr. 2019.

OLIVEIRA, Augusto M. F. Êxodos e encruzilhada da missa dos quilombos. - 2015. Tese (doutorado em Antropologia Social) - Universidade Federal de Santa Catarina, Florianópolis, 2015. 
PANTA, M. A. dos Santos. População negra em Londrina: processos migratórios, deslocamentos espaciais intra-urbanos e segregação. Dissertação (Mestrado em Ciências Sociais) - Universidade Estadual de Londrina, Londrina, 2013.

SALLES, Vicente. O Negro no Pará sob o regime da escravidão. 3 ed. rev. ampl. Belém: IAP, Programa Raízes, 2005.

SANTOS NETO, Ramiro Januário dos. Os imigrantes senegaleses na cidade de São Paulo: direitos humanos, discriminação e legislação migratória pertinente. Dissertação (Mestrado) - Departamento de Estudos Sociais - DES - Universidade de São Paulo, São Paulo, 2017.

SAYAD, A. A imigração ou os paradoxos da alteridade. Tradução Cristina Muracho. São Paulo: Editora da Universidade de São Paulo, 1998.

SEVERINO, Antônio Joaquim. Metodologia do Trabalho Científico. 23 ed. ver. e atual. São Paulo: Cortez, 2007.

SILVA, Kalina Vanderlei. SILVA, Maciel Henrique. Dicionário de conceitos históricos. . 2 ed. São Paulo: Contexto, 2009.

SILVA, Idelma Santiago da. Migração e Cultura no Sudeste do Pará: Marabá (19681988). 2006. Dissertação (Mestrado em História) - Universidade Federal de Goiás, Goiânia, 2006. 181f.

SOUZA, César Augusto Martins de. Migração e (Re)construção de Territorialidades na Transamazônica (1970-1990). In: BRITO, Adilson Júnior Ishihara; ROMANI, Carlos; BASTOS, Carlos Augusto. (org.). Limites fluentes: fronteiras e identidades na Amazônia Latina (século XVIII-XXI). Curitiba: CRV, 2013. 296p.

SOUZA, Regina M. de. Migração e trabalho: impactos do processo migratório na vivência cotidiana da mulher nordestina. 2014. Tese (Doutorado em Serviço Social) Universidade Estadual Paulista Júlio de Mesquita Filho, Franca, Franca Biblioteca Depositária: FCHS - UNESP. 2014. 208 f.

SMITH JÚNIOR, Francisco Pereira. Imigração espanhola na Amazônia: as colônias agrícolas e o desenvolvimento socioeconômico do Nordeste paraense (1890-1920). 2012. Tese (Doutorado em Desenvolvimento Sustentável do Tropico Úmido) Universidade Federal do Pará, Belém, 2012. 212 f..

SMITH JÚNIOR, Francisco Pereira. Migração Interna e Internacional na Amazônia: Sua Relação nas colônias agrícolas do Pará no início do Século XX. In: ARAGÓN, Luis Eduardo. (org.). Migração Interna na Pan - Amazônia. Belém: NAEA, 2013. 253 p.: il.; $29 \mathrm{~cm}$.

TAVARES, Gilson Q. Migração Interna Populacional e sua Participação no Desenvolvimento Regional No Final do Século XX. 2001. Dissertação (Mestrado em Administração Pública) - Fundação Getúlio Vargas, Rio de Janeiro, 2001. 107 f. 
TEISSERENC, Maria José da Silva Aquino; SANT'ANA JÚNIOR, Horácio Antunes de; ESTERCI, Neide. Ações locais e dinâmicas socioterritoriais emergentes na Amazônia e no Brasil. In: TEISSERENC, Maria José da Silva Aquino; SANT'ANA JÚNIOR, Horácio Antunes de; ESTERCI, Neide. (org.). Territórios, Mobilizações e conservação socioambiental. São Luís: EDUFMA, 2016.

WILliAMS, Raymond. Cultura e Materialismo. Tradução de André Glaser. São Paulo: Editora Unesp, 2011. 420p.

XAVIER, Giovana. Brancas de almas negras?: beleza, radicalização e cosmética na imprensa negra pós-emancipação (EUA, 1890- 1930). 2012.. Tese (doutorado) Departamento de História - Instituto de Filosofia e Ciências Humanas. Universidade Estadual de Campinas, Campinas, 2012. 